\title{
Parasitic Fitness of Fungicide-Resistant and -Sensitive Isolates of Alternaria solani
}

\author{
Mitchell J. Bauske and Neil C. Gudmestad, ${ }^{\dagger}$ Department of Plant Pathology, North Dakota State University, Fargo, 58105
}

\begin{abstract}
Resistance to chemistries of the succinate dehydrogenase inhibiting (SDHI) and quinone outside inhibiting (QoI) fungicides has developed rapidly in populations of Alternaria solani, the cause of early blight of potato. Reduced sensitivity to the anilinopyrimidine (AP) fungicide pyrimethanil has also been identified recently, determining that resistance to three chemical classes of fungicides is present within the A. solani population. Although no mutations have been characterized to confer resistance to APs, in A. solani five point mutations on three AsSdh genes have been determined to convey resistance to SDHIs, and the substitution of phenylalanine with leucine at position 129 (F129L) in the cytb gene confers resistance to QoIs. The objective of this study was to investigate the parasitic fitness of $A$. solani isolates with resistance to one or more of these chemical classes. A total of $120 \mathrm{~A}$. solani isolates collected from various geographical locations around the United States were chosen

for in vitro assessment, and 60 of these isolates were further evaluated in vivo. Fitness parameters measured were (i) spore germination in vitro, (ii) mycelial expansion in vitro, and (iii) aggressiveness in vivo. No significant differences in spore germination or mycelial expansion $(P=0.44$ and 0.51 , respectively) were observed among wild-type and fungicideresistant isolates in vitro. Only $A$. solani isolates possessing the D123E mutation were shown to be significantly more aggressive in vivo $(P<$ $0.0001)$ compared with wild-type isolates. These results indicate that fungicide-resistant $A$. solani isolates have no significant fitness penalties compared with sensitive isolates under the parameters evaluated regardless of the presence or absence of reduced sensitivity to multiple chemical classes. Results of these studies suggest that $A$. solani isolates with multiple fungicide resistances may compete successfully with wild-type isolates under field conditions.
\end{abstract}

Early blight, caused by the fungal pathogen Alternaria solani Sorauer, is an economically important foliar disease of potato (Solanum tuberosum L.) in many production areas across the United States. Because few commercially acceptable potato cultivars possess resistance, the most effective early blight management tactic is the frequent application of foliar fungicides from early in the growing season until vine desiccation (Gudmestad et al. 2013; Pscheidt and Stevenson 1988). Locally systemic and translaminar fungicides such as quinone outside inhibitors (QoIs), succinate dehydrogenase inhibitors (SDHIs), and anilinopyrimidines (APs) are widely applied for the management of early blight and achieve disease control at higher levels of disease pressure compared with standard protectant fungicides such as chlorothalonil and mancozeb (Pasche and Gudmestad 2008; Yellareddygari et al. 2016).

The QoI fungicides, which include chemistries such as azoxystrobin, trifloxystrobin, and pyraclostrobin, have a single site mode of action, interfering with the electron transport of the cytochrome $b_{1}$ complex (Bartlett et al. 2002), thereby inhibiting fungal respiration at mitochondrial complex III. Although initially providing high levels of disease control following their introduction in 1999, reduced efficacy provided by QoI fungicides was reported in less than 2 years owing to selection pressure placed on the fungus (Pasche et al. 2004, 2005). Resistance to QoI fungicides in many pathogens is attributed to the substitution of glycine with alanine at position 143 in the cytochrome b (cytb) gene (Bolton et al. 2013; Ishii et al. 2001; Köller et al. 2001; Sierotzki et al. 2000), but reduced sensitivity in A. solani has been shown to result from the substitution of phenylalanine with leucine at position 129 in the cytb gene (Pasche et al. 2005). By 2006, A. solani isolates possessing the F129L mutation were prevalent throughout much of the United States (Pasche and Gudmestad 2008).

The primary target site of SDHI fungicides is mitochondrial complex II at either the succinate ubiquinone reductase or succinate dehydrogenase complex, where molecules of this class of fungicide bind and inhibit fungal respiration (Avenot and Michailides 2010;

${ }^{\dagger}$ Corresponding author: N. C. Gudmestad; E-mail: neil.gudmestad@ndsu.edu Funding support for these studies was provided by Bayer CropSciences.

Accepted for publication 17 October 2017.

() 2018 The American Phytopathological Society
Sierotzki and Scalliet 2013). The widespread application of SDHI fungicides, beginning in 2005 with the registration of boscalid, placed significant selection pressure on pathogen populations, and mutations associated with SDHI resistance have been identified in Alternaria alternata, Botrytis cinerea, Corynespora cassiicola, Didymella bryoniae, Podosphaera xanthii, and A. solani (Avenot and Michailides 2010; Avenot et al. 2008b, 2012; Bardas et al. 2010; Ishii et al. 2011; Mallik et al. 2014). Five known point mutations have been identified to independently confer resistance to SDHI fungicides in A. solani (Mallik et al. 2014). Two of these mutations are detected on the $A s S d h B$ gene and include the substitutions of histidine to arginine (H278R) or tyrosine (H278Y) at codon 278, which result in a moderate or high level of resistance to SDHIs, respectively (Mallik et al. 2014). A single mutation on the AsSdhC gene resulting in the substitution of histidine to arginine (H134R) at codon 134 has also been identified as conferring high levels of resistance to SDHIs. Two additional mutations associated with resistance to SDHIs in A. solani have been detected on the $A s S d h D$ gene, including a substitution of aspartic to glutamic acid (D123E) at codon 123 conveying high levels of resistance and a substitution of histidine to arginine (H133R) at codon 133 conveying moderate levels of resistance (Mallik et al. 2014). A recent study in our laboratory determined that, in a diverse population of $A$. solani isolates collected across several years from 11 states, over $95 \%$ of isolates possessed mutations conferring SDHI resistance, and nearly all of those SDHI-resistant isolates also possessed the F129L mutation conferring resistance to QoI fungicides (Bauske et al. 2018).

The single-site mode of action of AP fungicides has been suggested to result in the inhibition of the secretion of fungal hydrolytic enzymes required during infection and inhibit the biosynthesis of methionine (Heye et al. 1994; Masner et al. 1994). APs have been used for the control of several pathogens including $B$. cinerea (Zhao et al. 2010) and Venturia inaequalis (Köller et al. 2005). However, resistance to APs has been reported in field isolates of $B$. cinerea of various crops (Amiri et al. 2013; Leroux et al. 1999; Myresiotis et al. 2007; Moyano et al. 2004), Penicillium spp. of apple and citrus (Kanetis et al. 2008; Xiao et al. 2011), and V. inaequalis of apple (FRAC 2015). In 2005, the AP pyrimethanil was registered for early blight control in potato. Unfortunately, in 2010, resistance was reported in A. solani isolates recovered in Idaho, with $19 \%$ of isolates collected determined to have reduced sensitivity to the fungicide (Fairchild et al. 2013). A recent study determined that 6 out of 245 A. solani isolates collected from 2010 to 2014 possessed reduced 
sensitivity to pyrimethanil in vitro and additionally found that isolates with reduced sensitivity were not controlled at most pyrimethanil doses in greenhouse efficacy assays (Fonseka and Gudmestad 2016).

The development of fungicide resistance in the field depends upon a number of different factors including presence of selection pressure, presence of a susceptible host, fungicide dosage, application intervals, persistence of fungicide applied, and fungicide application method (Peever and Milgroom 1995). However, one of the most important factors to consider in the development of fungicide resistance is the parasitic fitness of resistant isolates in the presence and absence of selection pressure (Dekker 1976). Parasitic fitness can be defined as the relative ability of a parasitic genotype or population to persist over time and contribute to the future gene pool (MacHardy et al. 2001) and is quantifiable using a number of different parameters including infection efficiency and amount of disease caused, or aggressiveness. Fitness costs can also be measured in terms of both predicted fitness (mycelial growth, spore germination, and spore production in vitro) and realized fitness (in vivo and competitive experiments) (Antonovics and Alexander 1989). Mutations associated with fungicide resistance may display deleterious pleiotropic effects, or fitness penalties, that become apparent in the absence of fungicide selection pressure (Jeger et al. 2008; Karaoglanidis et al. 2011). Many of the studies aimed at characterizing fitness penalties associated with fungicide resistance development have conflicting results, thus making definitive conclusions on the persistence of fungicide resistance difficult (Karaoglanidis et al. 2011). A limited number of studies have identified substantial fitness penalties in resistant isolates in both laboratory and field experiments (Iacomi-Vasilescu et al. 2008; Kadish and Cohen 1992; Karaoglanidis et al. 2001). Most research has indicated that parasitic fitness penalties are insignificant (Billard et al. 2012; Kim and Xiao 2011) or completely absent (Corio-Costet et al. 2010; Peever and Milgroom 1994) in fungicideresistant populations.

Due to the findings that a significant proportion of the A. solani population contains dual resistance to SDHI and QoI fungicides (Bauske et al. 2018; Gudmestad et al. 2013), and pyrimethanil resistance has been documented in a diverse A. solani population (Fonseka and Gudmestad 2016), detailed knowledge of the fitness of resistant isolates is needed to optimize fungicide resistance management strategies and achieve effective early blight disease management. The objectives of the research reported here were (i) to determine the predicted fitness in vitro of $A$. solani isolates possessing resistance to one or more fungicide chemical classes including SDHI, QoI, and AP fungicides and (ii) to determine the realized fitness in vivo of $A$. solani isolates possessing resistance to one or more chemical classes.

\section{Materials and Methods}

A. solani isolate selection. A total of $120 \mathrm{~A}$. solani isolates were evaluated during these studies. Isolates were selected based on origin and the presence or absence of mutations conferring fungicide resistance. A. solani isolates recovered from eight states including North Dakota, Minnesota, Nebraska, Texas, Colorado, Michigan, Idaho, and Wisconsin from 2011 through 2015 as a part of previous studies (Bauske et al. 2018; Mallik et al. 2014) were selected (Table 1). The 120 individual isolates evaluated in vitro were grouped for analysis based on the presence or absence of mutations conferring SDHI and QoI resistance as well as reduced sensitivity to APs. Among these isolates, four isolates had no fungicide resistance mutations and were regarded as wild type (Table 1). Sixteen A. solani isolates possessed only the F129L mutation conferring QoI resistance and were referred to as F129L-mutant isolates (Table 1). The remaining 100 A. solani isolates were grouped by SDHI mutation (H278Y, H278R, H134R, H133R, and D123E) and their resistance to QoI and AP chemical classes (Table 1). Also included were six isolates previously determined to have reduced sensitivity to the AP fungicide pyrimethanil (Fonseka and Gudmestad 2016) in addition to possessing resistance to SDHI and QoI fungicides, which were, therefore, resistant to three fungicide chemical classes.

Predicted fitness of fungicide-resistant and -sensitive A. solani isolates. Spore germination. Conidial germination assays were conducted as previously described (Gudmestad et al. 2013; Pasche et al. 2005) using 7- to 14-day-old cultures of $A$. solani maintained under continuous fluorescent light at $22 \pm 2{ }^{\circ} \mathrm{C}$. A glass rod was used to free conidia from the surface of the clarified V8 juice agar (CV8) medium using sterile distilled water under aseptic conditions. The conidial concentration of the suspension was determined using a hemocytometer and adjusted to $2 \times 10^{4}$ conidia/ml by adding sterile distilled water. A $150 \mu \mathrm{l}$ aliquot of the conidial suspension then was added to water agar medium containing $2 \%$ laboratorygrade agar (A360-500, Fisher Scientific, Pittsburgh, PA). Inoculated plates were incubated at $21^{\circ} \mathrm{C}$ under continuous light for $4 \mathrm{~h}$ prior to evaluation of conidial germination (Pasche et al. 2004). Following incubation, 50 conidia/plate were examined for the development of one germ tube at least as long as the conidium, or multiple germ tubes developing from one conidium, using an Olympus microscope model SZX2-ILLT (Olympus Corporation, Tokyo, Japan) at ×100 magnification. All experiments were performed twice with three replicates for each isolate (Karaoglanidis et al. 2011; Pasche et al. 2004). The $120 \mathrm{~A}$. solani isolates were tested for conidial germination in 12 trials, with 15 to 20 isolates included in each trial. Control isolates 13-1 (a wild-type A. solani isolate) and 526-3 (a QoI-resistant isolate) were included in each trial as internal controls to determine the reproducibility of these spore germination experiments. These specific

Table 1. Number of Alternaria solani isolates in each resistance mutation group

\begin{tabular}{|c|c|c|c|c|c|c|c|c|c|}
\hline Mutationa $^{a}$ & North Dakota & Minnesota & Nebraska & Texas & Idaho & Colorado & Michigan & Wisconsin & Total \\
\hline Wild type & 3 & $\ldots$ & $\ldots$ & $\ldots$ & $\ldots$ & 1 & $\ldots$ & $\ldots$ & $\overline{4}$ \\
\hline F129L & 7 & 7 & 1 & 1 & $\ldots$ & $\ldots$ & $\ldots$ & $\ldots$ & 16 \\
\hline $\mathrm{H} 278 \mathrm{Y}$ & 3 & $\ldots$ & 2 & $\ldots$ & 1 & $\ldots$ & $\ldots$ & $\ldots$ & 6 \\
\hline $\mathrm{H} 278 \mathrm{R}$ & 4 & $\ldots$ & 1 & $\ldots$ & 1 & $\ldots$ & $\ldots$ & $\ldots$ & 6 \\
\hline H134R & 2 & $\ldots$ & 1 & 1 & $\ldots$ & $\ldots$ & $\ldots$ & $\ldots$ & 4 \\
\hline H133R & 1 & $\cdots$ & $\ldots$ & $\ldots$ & $\cdots$ & 1 & $\cdots$ & $\cdots$ & 2 \\
\hline D123E & 2 & $\ldots$ & 3 & $\ldots$ & $\ldots$ & $\ldots$ & $\ldots$ & $\ldots$ & 5 \\
\hline $\mathrm{H} 278 \mathrm{Y} / \mathrm{F} 129 \mathrm{~L}$ & 3 & 2 & 2 & 4 & $\ldots$ & $\ldots$ & $\ldots$ & $\ldots$ & 11 \\
\hline $\mathrm{H} 278 \mathrm{R} / \mathrm{F} 129 \mathrm{~L}$ & 4 & 1 & 2 & 1 & 1 & 3 & $\ldots$ & 2 & 14 \\
\hline H134R/F129L & 4 & 2 & 3 & 3 & 1 & 2 & $\ldots$ & $\ldots$ & 15 \\
\hline H133R/F129L & 1 & 3 & 5 & 1 & 2 & 1 & 3 & $\ldots$ & 16 \\
\hline D123E/F129L & 4 & 1 & 4 & 3 & $\ldots$ & 1 & 2 & $\ldots$ & 15 \\
\hline H278Y/F129L/AP & $\ldots$ & 1 & $\ldots$ & 1 & $\begin{array}{l}\cdots \\
\cdots\end{array}$ & 1 & $\ldots$ & $\begin{array}{l}\cdots \\
\cdots\end{array}$ & 3 \\
\hline H134R/F129L/AP & $\ldots$ & $\ldots$ & $\ldots$ & 1 & $\ldots$ & $\ldots$ & $\ldots$ & $\ldots$ & 1 \\
\hline H133R/F129L/AP & $\ldots$ & $\ldots$ & $\ldots$ & $\ldots$ & 2 & $\ldots$ & $\ldots$ & $\ldots$ & 2 \\
\hline Total & 38 & 17 & 24 & 16 & 8 & 10 & 5 & 2 & 120 \\
\hline
\end{tabular}

${ }^{a}$ H278Y, H278R, H134R, H133R, and D123E mutation confer resistance to succinate dehydrogenase inhibiting fungicides, the F129L mutation confers resistance to quinone outside inhibiting fungicides, and AP denotes reduced sensitivity to the anilinopyrimidine fungicide pyrimethanil. 
isolates have been included throughout a number of fungicide resistance studies in A. solani as internal controls (Fonseka and Gudmestad 2016; Gudmestad et al. 2013; Mallik et al. 2014; Pasche et al. 2004, 2005).

Mycelial expansion. The identical A. solani isolates (Table 1) were also assessed for mycelial expansion in vitro. Agar sections from isolates were transferred onto CV8 medium and were incubated under $24 \mathrm{~h}$ fluorescent light at $22 \pm 2{ }^{\circ} \mathrm{C}$. After 4 days, 5-mm agar plugs were excised from the leading edge of growth and were inverted onto $90-\mathrm{mm}$ Petri plates containing $2 \%$ laboratory-grade agar. Two perpendicular measurements of mycelial growth for each isolate were measured after 7 days of incubation in the dark at $25 \pm 2^{\circ} \mathrm{C}$. Each $A$. solani isolate was evaluated a minimum of twice to determine mycelial expansion, with three replicates each trial (Fonseka and Gudmestad 2016; Karaoglanidis et al. 2011). The A. solani isolates 13-1 and 526-3, described earlier, were also included in each mycelial growth trial as internal controls.

Realized fitness of fungicide-resistant and -sensitive $A$. solani isolates. Aggressiveness. The aggressiveness of 60 fungicide-sensitive and -resistant $A$. solani isolates previously included in in vitro experiments was evaluated under greenhouse conditions as previously described (Fonseka and Gudmestad 2016; Gudmestad et al. 2013; Pasche et al. 2004, 2005; Pasche and Gudmestad 2008). A. solani isolates were selected based on origin, mutation presence, and resistance to one or multiple fungicide classes. Isolates inoculated in greenhouse experiments were maintained for 7 to 14 days on CV8 medium at $22 \pm 2{ }^{\circ} \mathrm{C}$ under constant fluorescent light. A glass rod was used to free conidia from the surface of the CV8 medium using sterile distilled water. The conidial concentration of the suspension was determined using a hemocytometer and adjusted to $2 \times 10^{5}$ conidia $/ \mathrm{ml}$. Tomato plants, cultivar Orange Pixie VFT Hybrid (Tomato Growers Supply Company, Fort Myers, FL) were grown in the greenhouse under natural light and ambient temperatures in $10-\mathrm{cm}^{3}$ pots containing Sunshine Mix LC1 (73 to $83 \% \mathrm{Ca}$ nadian sphagnum peat moss, perlite, and dolomite lime). Three tomato seeds were sown in each pot, and following emergence plants were thinned to obtain two uniformly sized plants per pot. Inoculations were performed when the first three leaves were fully expanded and plants were approximately $20 \mathrm{~cm}$ in height. Tomato plants were inoculated using $50 \mathrm{ml}$ of conidial suspension per plant using a Preval paint-spray gun (Preval Sprayer Division, Precision Valve Corporation, Yonkers, NY), and inoculated plants were kept for $24 \mathrm{~h}$ at $22 \pm 2^{\circ} \mathrm{C}$ in humid chambers (Phytotronic, Earth City, MO). High relative humidity was achieved in these chambers through mist application for $10 \mathrm{~s}$ every $2 \mathrm{~min}$. Plants then were transferred to specially built confinement chambers with four walls and open ceilings on greenhouse benches at $25 \pm 2{ }^{\circ} \mathrm{C}$ to minimize interisolate interference and were maintained with a daily application of water. The percentage disease severity, or percentage infected leaf area, on three fully expanded true leaves on each of two plants per pot, with one pot per replicate and three replicates, was assessed visually at 6, 9, and 12 days postinoculation (Gudmestad et al. 2013). Each of the 60 isolates was evaluated in two separate trials, and a total of 14 trials were conducted, with 7 to 10 isolates included in each trial. A control isolate, 1342-8, a wild-type A. solani isolate, was included as an internal control in each trial as a measure of reproducibility.

Statistical analyses. All in vitro experiments were performed twice in completely random design with three replicates for each A. solani isolate. Levene's test was conducted to test for homogeneity of variance among two independent experiments (Milliken and Johnson 1992). The isolates selected for this study were all field isolates and were divided into groups for analysis of variance (ANOVA) based on fungicide resistance, including wild-type isolates possessing no mutations or reduced sensitivity, as well as isolates with resistance to one or multiple chemical classes (Table 1). Percentage disease severity ratings were conducted in greenhouse assays as discussed earlier, and foliar disease severity was used to calculate area under the disease progress curve (AUDPC) as follows (Shaner and Finney 1977):

$$
\mathrm{AUDPC}=\sum_{i=1}^{n}\left[\left(\mathrm{~W}_{i+1}+\mathrm{W}_{i}\right) / 2\right]\left(\mathrm{t}_{i+1}-t_{i}\right)
$$

where $\mathrm{W}_{i}$ is the percentage foliar disease severity at the $i$ th observation, $t_{i}$ is the time in days at the $i$ th observation, and $n$ is the total number of observations. The relative AUDPC (RAUDPC) was calculated for each treatment of the replicated trials from each year by dividing AUDPC values by the total area of the graph and was analyzed using ANOVA (PROC GLM, SAS version 9.3, SAS Institute, Cary, NC). Fisher's protected least significant difference (LSD) test $(P=0.05)$ was used to differentiate mean RAUDPC values (Pasche and Gudmestad 2008). For in vitro experiments, ANOVA was performed on the combined results using PROC GLM in SAS, and differences among groups were compared using Fisher's protected LSD test $(P=0.05)$. In all in vitro and in vivo studies, control isolates were used in each trial as described earlier to determine reproducibility of the assay. Assay reproducibility calculations were applied to the internal control isolates 13-1 and 526-3 (Wong and Wilcox 2002), generating limits for $95 \%$ confidence intervals for each internal control. Trials in which the data of the internal control for each assay were within the $95 \%$ confidence interval were included in further statistical analyses (Fonseka and Gudmestad 2016; Wong and Wilcox 2002).

\section{Results}

Determination of predicted fitness of fungicide-resistant and -sensitive A. solani isolates in vitro. Spore germination. Mean spore germination percentage among groups ranged between $98.8 \%$ for H278R mutants and $99.9 \%$ for D123E mutants, but these groups were not significantly different, indicating similar spore germination among grouped wild-type and SDHI-resistant isolates of A. solani (Table 2, Fig. 1). Although there was variability in the percentage of spore germination among isolates within each fungicide resistance mutation group, the coefficient of variation among isolates for all groups was 0.10 or lower (Table 2). A. solani isolates with dual resistance to SDHI and QoI fungicides were also determined to have mean spore germination percentages that were not significantly different from wild-type isolates (Fig. 1). The mean spore germination of dual-resistant isolates, as well as mean spore germination of isolates resistant to three chemical classes, was also not significantly different from isolates only possessing a single mutation conferring resistance to one chemical class (Fig. 1).

Mycelial expansion. Mean mycelial expansion among grouped wild-type and fungicide-resistant isolates was not significantly different $(P=0.51)$ (Fig. 2). The coefficient of variation for mycelial expansion among isolates within resistance groups varied between 0.05 for isolates with the D123E mutation to 0.17 for isolates with the H278R mutation, and confidence intervals were similar among isolates within each of the resistance groups (Table 2). Wild-type isolates were determined to have a mean mycelial expansion of $51.8 \mathrm{~mm}$, which was not significantly higher than SDHI-mutant isolate groups (H278Y, H278R, H134R, H133R, and D123E mutants) (Fig. 2). There was also no significant difference in mean mycelial expansion among any of the SDHI-mutant groups, which ranged from $50.9 \mathrm{~mm}$ for isolates possessing the H278R mutation to $52.1 \mathrm{~mm}$ for isolates with the D123E mutation (Table 2, Fig. 2). No significant difference was observed among grouped isolates possessing resistance to more than one chemical class compared with $A$. solani isolates resistant to a single chemical class or compared with wildtype isolates (Fig. 2). Isolates with either the H278Y, H133R, or H134R mutation in addition to the F129L mutation and reduced sensitivity to pyrimethanil were determined to have mean mycelial expansion values of 51.4, 51.2, and $51.3 \mathrm{~mm}$, respectively, which were not significantly different from wild-type isolates or groups of isolates possessing resistance to one or two chemical classes (Fig. 2)

Determination of realized fitness of fungicide-resistant and -sensitive A. solani isolates in vivo. Aggressiveness. All A. solani isolates evaluated for aggressiveness in greenhouse assays caused severe disease symptoms on tomato leaves. There were significant differences in mean RAUDPC values of wild-type and fungicideresistant isolates $(P<0.0001)$, with D123E-mutant isolates having a mean RAUDPC value of 0.0726 , significantly higher than the mean RAUDPC value of 0.0583 for wild-type isolates (Table 2, Fig. 3). The coefficient of variation among RAUDPC values of individual 
isolates within each resistance group ranged from 0.02 for isolates with the D123E mutation to 0.20 among individual isolates possessing the F129L mutation, suggesting variability among individual isolates in particular groups even though mean RAUDPC values among resistance groups were similar (Table 2). A. solani isolates with the D123E mutation were also determined to have significantly higher RAUDPC values compared with other SDHI-mutant groups of H278Y, H278R, H134R, and H133R-mutant isolates (Fig. 3). H278Rmutant isolates were determined to have an RAUDPC value of 0.0583 , which was the lowest of all grouped SDHI-resistant isolates but was not significantly different from wild-type isolates or $\mathrm{H} 278 \mathrm{Y}$, H134R, and H133R-mutant isolates. Only the D123E mutation isolate group was found to have significantly higher aggressiveness in vivo compared with isolates with other SDHI mutations (Fig. 3). A. solani isolates possessing both the D123E mutation and the F129L mutation conveying dual resistance to SDHIs and QoIs were also determined to have a significantly higher mean RAUDPC value compared with wild-type isolates and other mutant groups. Additionally, A. solani isolates possessing triple resistance to SDHIs, QoIs, and APs by virtue of possessing the H278Y, H134R, or H133R, the F129L mutation, and reduced sensitivity to pyrimethanil had mean RAUDPC values of $0.0588,0.0583$, and 0.0587 , respectively, which were not significantly different from the mean RAUDPC value of 0.0583 for wild-type isolates (Fig. 3). All fungicide resistance groups, regardless

Table 2. Variation in spore germination, mycelial expansion, and aggressiveness among individual Alternaria solani isolates within fungicide resistance groups

\begin{tabular}{|c|c|c|c|c|c|c|c|c|c|}
\hline \multirow[b]{2}{*}{ Mutation } & \multicolumn{6}{|c|}{ In vitro } & \multicolumn{3}{|c|}{ In vivo } \\
\hline & $\begin{array}{c}\text { Spore } \\
\text { germination }(\%)^{\mathbf{a}}\end{array}$ & $\mathbf{C V}^{\mathbf{b}}$ & $95 \% \mathbf{C I}^{\mathbf{c}}$ & $\begin{array}{c}\text { Mycelial } \\
\text { expansion }(\mathbf{m m})^{\mathbf{a}}\end{array}$ & $\mathbf{C V}^{\mathbf{b}}$ & $95 \% \mathbf{C I}^{\mathrm{c}}$ & $\begin{array}{l}\text { Aggressiveness } \\
\text { (RAUDPC) }^{\mathbf{a}}\end{array}$ & $\mathbf{C V}^{\mathbf{b}}$ & $95 \% \mathrm{CI}^{\mathrm{c}}$ \\
\hline Wild type & 99.7 & 0.04 & $99.5-99.9$ & 51.8 & 0.13 & $50.5-52.7$ & 0.0583 & 0.15 & $0.0580-0.0585$ \\
\hline SF129L & 99.7 & 0.05 & 99.4-99.9 & 51.7 & 0.12 & $50.9-52.4$ & 0.0585 & 0.20 & $0.0579-0.0589$ \\
\hline $\mathrm{H} 278 \mathrm{Y}$ & 99.6 & 0.03 & $99.3-99.8$ & 51.3 & 0.11 & $50.6-51.9$ & 0.0585 & 0.19 & $0.0583-0.0588$ \\
\hline $\mathrm{H} 278 \mathrm{R}$ & 98.9 & 0.04 & $98.5-99.2$ & 50.9 & 0.17 & $49.8-51.7$ & 0.0585 & 0.10 & $0.0583-0.0587$ \\
\hline H134R & 99.8 & 0.03 & $99.4-99.9$ & 52.1 & 0.09 & $51.5-52.7$ & 0.0587 & 0.17 & $0.0583-0.0590$ \\
\hline H133R & 98.8 & 0.07 & $98.6-99.2$ & 51.9 & 0.12 & $51.3-52.6$ & 0.0583 & 0.20 & $0.0579-0.0587$ \\
\hline D123E & 99.9 & 0.02 & $99.7-100$ & 52.1 & 0.05 & $51.8-52.4$ & 0.0726 & 0.02 & $0.0725-0.0728$ \\
\hline $\mathrm{H} 278 \mathrm{Y} / \mathrm{F} 129 \mathrm{~L}$ & 99.7 & 0.05 & $99.4-99.8$ & 51.8 & 0.07 & $51.4-52.3$ & 0.0584 & 0.15 & $0.0580-0.0589$ \\
\hline $\mathrm{H} 278 \mathrm{R} / \mathrm{F} 129 \mathrm{~L}$ & 98.8 & 0.10 & $98.3-99.2$ & 50.8 & 0.15 & $49.8-51.9$ & 0.0584 & 0.17 & $0.0581-0.0588$ \\
\hline H134R/F129L & 99.7 & 0.02 & $99.3-99.8$ & 51.7 & 0.10 & $51.1-52.0$ & 0.0586 & 0.12 & $0.0583-0.0589$ \\
\hline H133R/F129L & 99.1 & 0.03 & $98.5-99.2$ & 51.6 & 0.04 & $51.4-51.8$ & 0.0585 & 0.19 & $0.0582-0.0589$ \\
\hline $\mathrm{D} 123 \mathrm{E} / \mathrm{F} 129 \mathrm{~L}$ & 99.6 & 0.02 & $99.4-99.8$ & 52.2 & 0.10 & $51.6-52.7$ & 0.0707 & 0.03 & $0.0705-0.0709$ \\
\hline H278Y/F129L/AP & 99.7 & 0.02 & $99.5-99.9$ & 51.4 & 0.08 & $51.0-51.7$ & 0.0588 & 0.10 & $0.0585-0.0590$ \\
\hline H134R/F129L/AP & 99.7 & 0.05 & $99.3-99.9$ & 51.3 & 0.05 & $50.9-51.6$ & 0.0583 & 0.15 & $0.0578-0.0587$ \\
\hline H133R/F129L/AP & 98.8 & 0.07 & $98.7-99.3$ & 51.2 & 0.06 & $51.0-51.5$ & 0.0587 & 0.13 & $0.0582-0.0590$ \\
\hline
\end{tabular}

${ }^{a}$ Mean of individual Alternaria solani isolates in resistance groups for spore germination, mycelial expansion, and aggressiveness.

${ }^{\mathrm{b}}$ Coefficient of variation.

c $95 \%$ confidence interval.

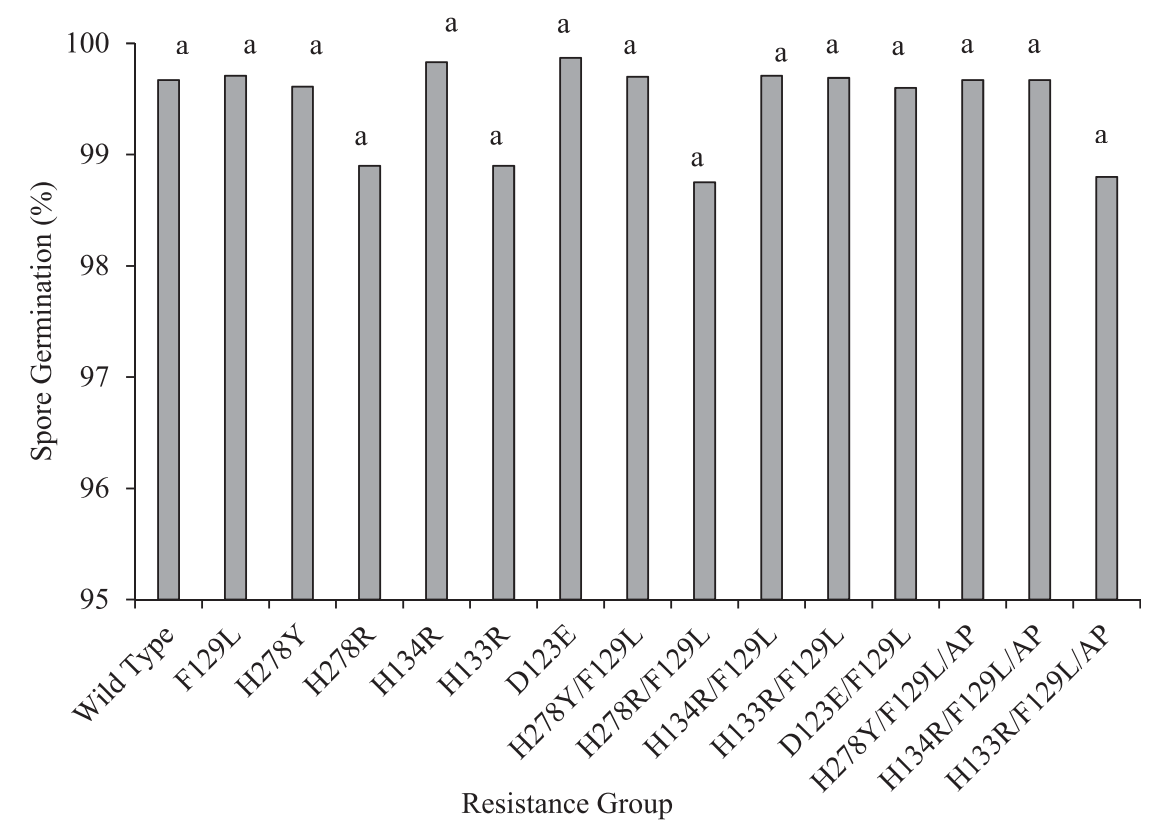

Fig. 1. Spore germination of grouped fungicide-resistant and -sensitive isolates of Alternaria solani. The H278Y, H278R, H134R, H133R, and D123E mutations are associated with succinate dehydrogenase inhibitor resistance. The F129L mutation is associated with quinone outside inhibitor resistance. AP denotes isolates found to have reduced sensitivity to pyrimethanil by Fonseka and Gudmestad (2016). Groups with several denotations possess resistance to multiple chemical classes. Columns with the same letter are not significantly different according to Fisher's protected least significant difference test $(P<0.05)$. 
of possessing resistance to one, two, or three fungicide chemical classes, were similar in in vivo aggressiveness compared with wild-type isolates (Fig. 3).

\section{Discussion}

This is the first study evaluating parasitic fitness of SDHI-resistant A. solani isolates and isolates resistant to multiple chemical classes. The recent documentation of the widespread fungicide resistance in A. solani populations across the United States (Fairchild et al. 2013; Fonseka and Gudmestad 2016; Gudmestad et al. 2013; Mallik et al. 2014; Tymon and Johnson 2014) necessitates the implementation of fungicide-resistance management strategies that can functionally delay further resistance development. To successfully implement these strategies and to determine how effective they will be at delaying the selection of resistant strains, knowledge of parasitic fitness is critical because resistance may be accompanied by fitness penalties that influence the risk of resistance build-up in the absence of selection pressure (Mikaberidze et al. 2014; Milgroom et al. 1989). Thus, the characterization of resistant isolates in terms of fitness may allow us to predict the behavior of the pathogen population (Avenot and Michailides 2010). In the current study, parasitic fitness was evaluated both in terms of "predicted fitness" (measurement of parameters in vitro) and "realized fitness" (evaluation of fungicide-resistant and wild-type isolates in vivo) (Antonovics and Alexander 1989).

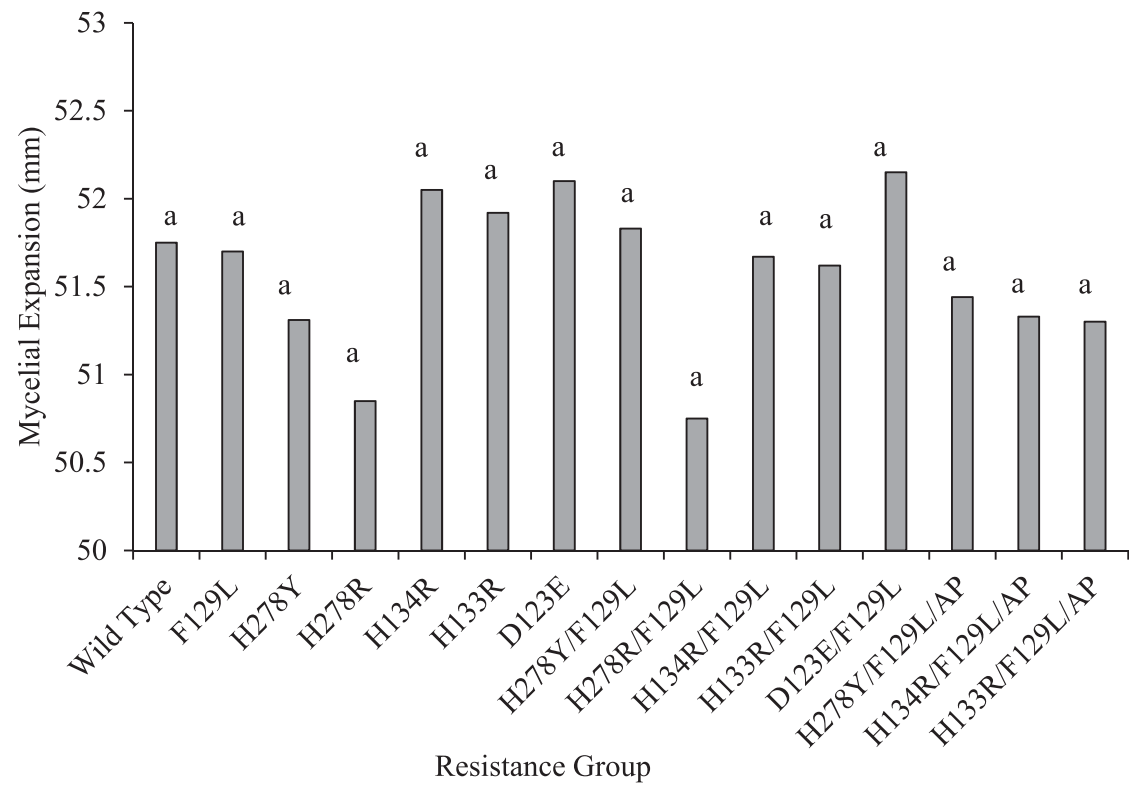

Fig. 2. Mycelial expansion of grouped fungicide-resistant and -sensitive isolates of Alternaria solani. The H278Y, H278R, H134R, H133R, and D123E mutations are associated with succinate dehydrogenase inhibitor resistance. The $\mathrm{F} 129 \mathrm{~L}$ mutation is associated with quinone outside inhibitor resistance. AP denotes isolates found to have reduced sensitivity to pyrimethanil by Fonseka and Gudmestad (2016). Groups with several denotations possess resistance to multiple chemical classes. Columns with the same letter are not significantly different according to Fisher's protected least significant difference test $(P<0.05)$.

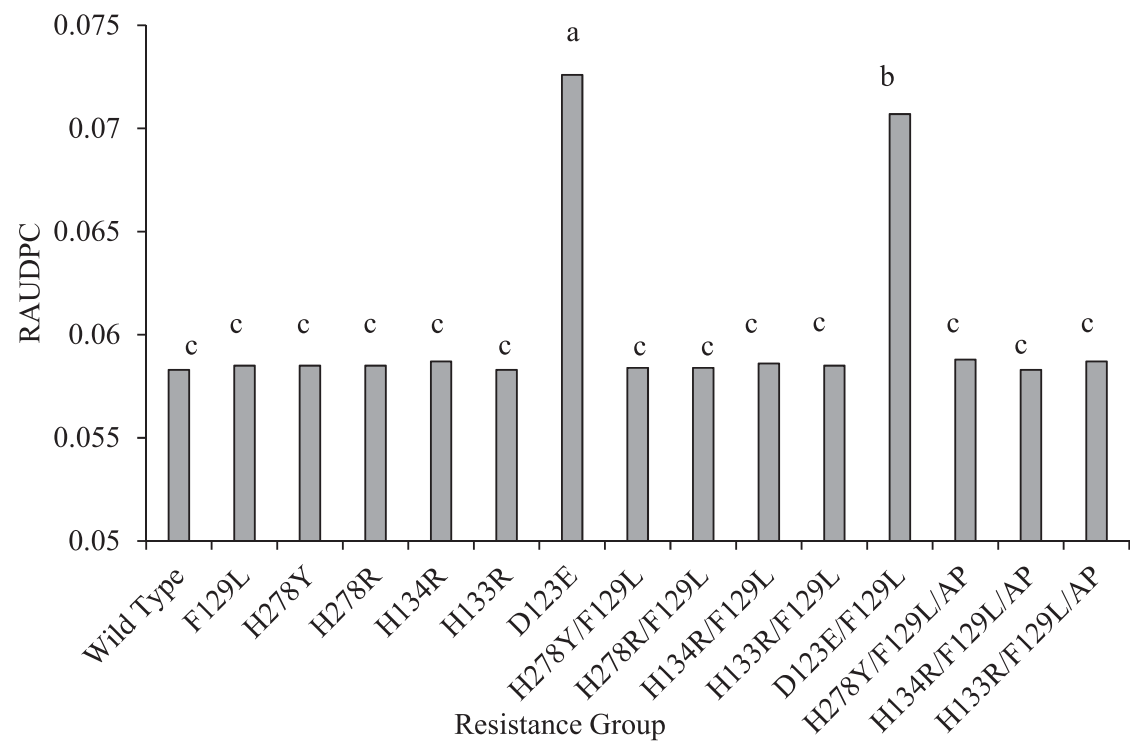

Fig. 3. Aggressiveness (relative area under the disease progress curve [RAUDPC]) of grouped fungicide-resistant and -sensitive isolates of Alternaria solani as determined in greenhouse assays. The H278Y, H278R, H134R, H133R, and D123E mutations are associated with succinate dehydrogenase inhibitor resistance. The F129L mutation is associated with quinone outside inhibitor resistance. AP denotes isolates found to have reduced sensitivity to pyrimethanil by Fonseka and Gudmestad (2016). Groups with several denotations possess resistance to multiple chemical classes. Columns with the same letter are not significantly different according to Fisher's protected least significant difference test $(P<0.05)$. 
Wild-type and fungicide-resistant $A$. solani isolates in this study were shown to have no significant differences in in vitro spore germination or mycelial expansion, suggesting the lack of any fitness penalty under these parameters in vitro. Similarly, many other studies evaluating fungicide-resistant isolates of several pathogens have identified no differences in predicted fitness parameters (Billard et al. 2012; Corio-Costet et al. 2010; Kim and Xiao 2011; Peever and Milgroom 1994). For example, boscalid-resistant and -sensitive isolates of A. alternata of pistachio were evaluated and revealed to have no significant differences in predicted fitness components of spore germination, hyphal growth, or sporulation, and following successive subculturing on non-fungicide-amended potato dextrose agar, resistant isolates were stable after multiple generations in the absence of selection pressure (Avenot and Michailides 2007). Similarly, in other pathogens, such as D. bryoniae (Stevenson et al. 2008) and $C$. cassiicola (Miyamoto et al. 2009), no differences in the mycelial growth rates were observed between boscalid-resistant and -sensitive field isolates on nonamended media. A previous study with A. solani evaluated in vitro and in vivo fitness of isolates possessing the F129L mutation conferring QoI resistance and found that F129L mutants, compared with sensitive isolates, had significantly lower spore germination in vitro but higher aggressiveness in vivo (Pasche and Gudmestad 2008). This suggests the lack of spore germination is not a significant fitness penalty causing reduced competition of F129L mutants in the field. A few studies related to the fitness and competitive ability of QoI laboratory-induced mutants of Cercospora beticola and $B$. cinerea have identified fitness penalties (Malandrakis et al. 2006; Markoglou et al. 2006), but it is likely that this was due to pleiotropic effects of several accumulated mutations induced by mutagenesis during experimentation (Karaoglanidis et al. 2011). Another study evaluating laboratory-induced boscalid-resistant mutants of Penicillium expansum found no difference between resistant mutants and wild-type isolates in a number of in vitro fitness parameters including osmotic sensitivity, spore production, and spore germination (Malandrakis et al. 2017). However, most $P$. expansum laboratory-induced mutants did show a significant reduction in mycelial growth compared with wild-type isolates, but they also demonstrated an increase in mycotoxin production relative to wild-type isolates (Malandrakis et al. 2017). These data suggest the existence of fitness penalties in SDHI- or QoI-resistant isolates that are not just pathogen dependent but may also depend upon the fitness component evaluated.

Perhaps the most interesting finding of these studies is that $A$. solani isolates possessing the D123E mutation on the $A s S d h D$ gene conferring SDHI resistance were found to have significantly higher aggressiveness in vivo compared with wild-type isolates, as well as isolates possessing other mutations conferring SDHI resistance. This may explain why isolates possessing the D123E mutation, which conveys a high level of resistance to the SDHI fungicides boscalid and penthiopyrad (Mallik et al. 2014), were collected at increasingly higher frequencies throughout a multiyear spatial survey by our research group (Bauske et al. 2018). All D123E-mutant $A$. solani isolates, regardless of the presence of resistance to $\mathrm{QoI}$ or AP fungicides, were shown to have significantly higher aggressiveness in vivo compared with wild-type isolates. This suggests the absence of any fitness penalty associated with the accumulation of other fungicide resistance. Other studies have also suggested a fitness advantage of SDHI-resistant isolates, such as with boscalid-resistant isolates of A. alternata in pistachio, which were recovered from plant tissue at high proportions before any application of fungicides during the growing season (Avenot et al. 2008a). An increase of fitness was also demonstrated in $B$. cinerea isolates possessing the $\mathrm{H} 272 \mathrm{R}$ mutation in the $B c S d h B$ gene, and $\mathrm{H} 272 \mathrm{R}$ mutants were also recovered at a high frequency within SDHI-resistant populations of B. cinerea (Fernández-Ortuño et al. 2008; Kim and Xiao 2010; Veloukas et al. 2014). Other studies have found that A. alternata isolates from peach that possess the $\mathrm{H} 277 \mathrm{Y}$ or H134R mutations conferring SDHI-resistance did not suffer any obvious fitness penalties and that H277Y-mutant A. alternata isolates were found to have greater fitness than boscalid-sensitive isolates (Fan et al. 2015).

This study also found no differences in spore germination or mycelial expansion between sensitive isolates and A. solani isolates possessing resistance to several chemical classes. Although this is the first study evaluating the fitness of $A$. solani isolates resistant to multiple chemical classes, previous studies have identified or refuted fitness costs attributed to dual fungicide resistance in other pathogens. In $B$. cinerea isolates with dual resistance to QoIs and SDHIs, isolates possessing the G143A mutation conveying a high level of resistance to QoIs and different $S d h B$ mutations were shown to suffer significant fitness costs, including lower values for multiple fitness components and the dominance of sensitive $B$. cinerea isolates in competition experiments (Veloukas et al. 2014). Other fitness and competitive penalties have been identified in $B$. cinerea isolates resistant to five or more chemical classes (Chen et al. 2016). In contrast, other studies have reported that $B$ cinerea isolates collected from apple with dual resistance to SDHIs and QoIs expressed fitness similar to that of sensitive isolates (Kim and Xiao 2011). However, $B$. cinerea isolates possessing multiple mutations in the $B c S d h B$ gene conferring resistance to SDHIs demonstrated a high fitness cost compared with wild-type strains (Laleve et al. 2013), suggesting fitness penalties attributed to the accumulation of SDHI mutations in the same isolate. Evaluation of A. alternata isolates resistant to SDHIs, QoIs, and methyl benzimidazoles has found both fitness costs and higher fitness of resistant isolates depending on mutation and fitness parameter (Fan et al. 2015). Furthermore, A. alternata isolates possessing the D123E mutation had hypersensitivity to oxidative stress and weak sporulation. Although the current study suggests higher fitness of D123E-mutant $A$. solani isolates, the same mutation may or may not be associated with fitness penalties in different pathogens (Karaoglanidis et al. 2011; Rallos et al. 2014). Nothing is known about additional genetic variation or genetic background of $A$. solani isolates possessing the D123E mutation, and further research utilizing whole-genome sequencing to associate polymorphisms with reduced sensitivity to fungicides or fitness may be necessary.

The absence of obvious fitness penalties in A. solani isolates resistant to a single or multiple chemical classes in this study has important implications for the management of early blight of potato. The research reported here clearly indicates that isolates of $A$. solani resistant to SDHI, QoI, and/or AP fungicides have similar in vitro and in vivo parasitic fitness compared with sensitive isolates, which suggests that resistant isolates may successfully compete with sensitive isolates under field conditions. These data also substantiate the previous findings that $A$. solani isolates possessing the F129L mutations do not suffer from substantial fitness penalties. Additional studies are needed to further elucidate the competitive fitness of fungicide-resistant isolates of $A$. solani in the presence and absence of a fungicide selection pressure. For example, a previous study on demethylation inhibitor (DMI) sensitivity in A. solani documented a significant loss in sensitivity to difenoconazole and metconazole in isolates collected in 2010 to 2012 compared with a baseline population (Fonseka and Gudmestad 2016). However, A. solani isolates collected in 2013 to 2015 were as sensitive to these DMI fungicides as the baseline population, suggesting there may be a fitness penalty associated with DMI resistance in the early blight fungus. Future research will focus on competition experiments using mixed inocula of isolates with equal aggressiveness at various ratios. Inoculation experiments in vivo using mixtures of sensitive $A$. solani isolates and isolates possessing mutations conferring fungicide resistance, and the determination of their recovery ratios from symptomatic plants, will provide an additional assessment of competitive fitness by more closely simulating an agricultural environment. However, this study suggests the absence of any fitness penalties under these evaluation parameters. It can therefore be reasonably predicted that the frequency of SDHI-, QoI-, and AP-resistant A. solani isolates will be maintained in the pathogen population in the absence of selection pressure and lead to a continual decline in the performance of certain chemistries in these classes.

\section{Literature Cited}

Amiri, A., Heath, S. M., and Peres, N. A. 2013. Phenotypic characterization of multifungicide resistance in Botrytis cinerea isolates from strawberry fields in Florida. Plant Dis. 97:393-401. 
Antonovics, J., and Alexander, H. M. 1989. The concept of fitness in plant- fungal pathogen systems. Pages 185-214 in: Plant Disease Epidemiology. Vol. 2. K. J. Leonard and W. E. Fry, eds. McGraw and Hill, New York.

Avenot, H. F., and Michailides, T. J. 2007. Resistance to boscalid fungicide in Alternaria alternata isolates from pistachio in California. Plant Dis. 91:1345-1350.

Avenot, H. F., and Michailides, T. J. 2010. Progress in understanding molecular mechanisms and evolution of resistance to succinate dehydrogenase inhibiting (SDHI) fungicides in phytopathogenic fungi. Crop Prot. 29:643-651.

Avenot, H. F., Morgan, D. P., and Michailides, T. J. 2008a. Resistance to pyraclostrobin, boscalid and multiple resistance to Pristine ${ }^{\circledR}$ (pyraclostrobin + boscalid) fungicide in Alternaria alternata causing Alternaria late blight of pistachios in California. Plant Pathol. 57:135-140.

Avenot, H. F., Sellam, A., Karaoglanidis, G., and Michailides, T. J. 2008 b. Characterization of mutations in the iron-sulphur subunit of succinate dehydrogenase correlating with boscalid resistance in Alternaria alternata from California pistachio. Phytopathology 98:736-742.

Avenot, H. F., Thomas, A., Gitaitis, R. D., Langston, D. B., Jr., and Stevenson, K. 2012. Molecular characterization of boscalid- and penthiopyrad-resistant isolates of Didymella bryoniae and assessment of their sensitivity to fluopyram. Pest Manag. Sci. 68:645-651.

Bardas, G. A., Veloukas, T., Koutita, O., and Karaoglanidis, G. S. 2010. Multiple resistance of Botrytis cinerea from kiwifruit to SDHIs, QoIs and fungicides of other chemical groups. Pest Manag. Sci. 66:967-973.

Bartlett, D. W., Clough, J. M., Godwin, J. R., Hall, A. A., Hamer, M., and ParrDobrzanski, B. 2002. The strobilurin fungicides. Pest Manag. Sci. 58:649-662.

Bauske, M. J., Mallik, I., Yellareddygari, S. K. R., and Gudmestad, N. C. 2018. Spatial and temporal distribution of mutations conferring QoI and SDHI resistance in Alternaria solani across the United States. Plant Dis. doi.org/ 10.1094/PDIS-06-17-0852-RE

Billard, A., Fillinger, S., Leroux, P., Lachaise, H., Beffa, R., and Debieu, D. 2012. Strong resistance to the fungicide fenhexamid entails a fitness cost in Botrytis cinerea, as shown by comparisons of isogenic strains. Pest Manag. Sci. 68: 684-691.

Bolton, M. D., Rivera, V., and Secor, G. 2013. Identification of the G143A mutation associated with QoI resistance in Cercospora beticola field isolates from Michigan, United States. Pest Manag. Sci. 69:35-39.

Chen, S. N., Luo, C. X., Hu, M. J., and Schnabel, G. 2016. Fitness and competitive ability of Botrytis cinerea isolates with resistance to multiple chemical classes of fungicides. Phytopathology 106:997-1005.

Corio-Costet, M.-F., Dufour, M.-C., Cigna, J., Abadie, P., and Chen, W.-J. 2010. Diversity and fitness of Plasmopara viticola isolates resistant to QoI fungicides. Eur. J. Plant Pathol. 129:315-329.

Dekker, J. 1976. Acquired resistance to fungicides. Annu. Rev. Phytopathol. 14: 405-428.

Fairchild, K. L., Miles, T. D., and Wharton, P. S. 2013. Assessing fungicide resistance in populations of Alternaria in Idaho potato fields. Crop Prot. 49:31-39.

Fan, Z., Yang, J.-H., Fan, F., Lou, C.-X., and Schnabel, G. 2015. Fitness and competitive ability of Alternaria alternata field isolates with resistance to SDHI, QoI, and MBC fungicides. Plant Dis. 99:1744-1750.

Fernández-Ortuño, D., Torés, J. A., Vicente, A. D., and Pérez-Garca, A. 2008. Mechanisms of resistance to QoI fungicides in phytopathogenic fungi. Int. Microbiol. 11:1-9.

Fonseka, D. L., and Gudmestad, N. C. 2016. Spatial and temporal sensitivity of Alternaria species associated with potato foliar diseases to demethylation inhibiting and anilino-pyrimidine fungicides. Plant Dis. 100:1848-1857.

Fungicide Resistance Action Committee (FRAC). 2015. FRAC Code List. Fungicides sorted by mode of action (including FRAC code numbering). Online publication. CropLife Int'1, Brussels, Belgium.

Gudmestad, N. C. S., Arabiat, S., Pasche, J. S., and Miller, J. S. 2013. Prevalence and impact of SDHI fungicide resistance in Alternaria solani. Plant Dis. 97: 952-960.

Heye, U. J., Speich, J., Siegle, H., Steinemann, A., Forster, B., Knauf-Beiter, G., Herzog, J., and Hubele, A. 1994. CGA 219417: A novel broad-spectrum fungicide. Crop Prot. 13:541-549.

Iacomi-Vasilescu, B., Bataille-Simoneau, N., Campion, C., Dongo, A., Laurent, E., Serandat, I., Hamon, B., and Simoneau, P. 2008. Effect of null mutations in the AbNIK1 gene on saprophytic and parasitic fitness of Alternaria brassicicola isolates highly resistant to dicarboximide fungicides. Plant Pathol. 57:937-947.

Ishii, H., Fraaije, B. A., Sugiyama, T., Noguchi, K., Nishimura, K., Takeda, T., Amano, T., and Hollomon, D. W. 2001. Occurrence and molecular characterization of strobilurin resistance in cucumber powdery mildew and downy mildew. Phytopathology 91:1166-1171.

Ishii, H., Miyamoto, T., Ushio, S., and Kakishima, M. 2011. Lack of crossresistance to a novel succinate dehydrogenase inhibitor, fluopyram, in highly boscalid-resistant isolates of Corynespora cassiicola and Podosphaera xanthii. Pest Manag. Sci. 67:474-482.

Jeger, M. J., Wijngaarden, P. J., and Hoekstra, R. F. 2008. Adaptation to the cost of resistance in a haploid clonally reproducing organism: The role of mutation, migration and selection. J. Theor. Biol. 252:621-632.

Kadish, D., and Cohen, Y. 1992. Overseasoning of metalaxyl-sensitive and metalaxyl-resistant isolates of Phytophthora infestans in potato tubers weeks after inoculation. Phytopathology 82:887-889.
Kanetis, L., Förster, H., Jones, C. A., Borkovich, K. A., and Adaskaveg, J. E. 2008. Characterization of genetic and biochemical mechanisms of fludioxonil and pyrimethanil resistance in field isolates of Penicillium digitatum. Phytopathology 98:205-214

Karaoglanidis, G., Thanassoulopoulos, C., and Ioannidis, P. 2001. Fitness of Cercospora beticola field isolates resistant and sensitive to demethylation inhibitor fungicides. Eur. J. Plant Pathol. 107:337-347.

Karaoglanidis, G. S., Luo, Y., and Michailides, T. J. 2011. Competitive ability and fitness of Alternaria alternata isolates resistant to QoI fungicides. Plant Dis. 95: 178-182.

Kim, Y. K., and Xiao, C. L. 2010. Resistance to pyraclostrobin and boscalid in populations of Botrytis cinerea from stored apples in Washington State. Plant Dis. 94:604-612.

Kim, Y. K., and Xiao, C. L. 2011. Stability and fitness of pyraclostrobinand boscalid-resistant phenotypes in field isolates of Botrytis cinerea from apple. Phytopathology 101:1385-1391.

Köller, W., Avila-Adame, C., Olaya, G., and Zheng, D. 2001. Resistance to strobilurin fungicides. Pages 215-229 in: Agrochemical Resistance: Extent, Mechanism, and Detection. J. M. Clark and I. Yamaguchi, eds. American Chemical Society, Washington, D.C.

Köller, W., Wilcox, W. F., and Parker, D. M. 2005. Sensitivity of Venturia inaequalis populations to anilinopyrimidine fungicides and their contribution to scab management in New York. Plant Dis. 89:357-365.

Laleve, A., Walker, A.-S., Gamer, S., Toquin, V., Debieu, D., and Fillinger, S. 2013. From enzyme to fungal development or how SdhB mutations impact respiration, fungicide resistance and fitness in the grey mold agent Botrytis cinerea. (Abstr.) Page 80 in: Modern Fungicides and Antifungal Compounds VII. Proceedings of the 17th International Reinhardsbrunn Symposium, Friedrichroda, Germany.

Leroux, P., Chapeland, F., Desbrosses, D., and Gredt, M. 1999. Patterns of crossresistance to fungicides in Botryotinia fuckeliana (Botrytis cinerea) isolates from French vineyards. Crop Prot. 18:687-697.

MacHardy, W. E., Gadoury, D. M., and Gessler, C. 2001. Parasitic and biological fitness of Venturia inaequalis: Relationship to disease management strategies. Plant Dis. 85:1036-1051.

Malandrakis, A. A., Markoglou, A. N., Nikou, D. C., Vontas, J. G., and Ziogas, B. N. 2006. Biological and molecular characterization of laboratory mutants of Cercospora beticola resistant to Qo inhibitors. Eur. J. Plant Pathol. 116:155-166.

Malandrakis, A. A., Vattis, K. N., Markoglou, A. N., and Karaoglanidis, G. S. 2017. Characterization of boscalid-resistance conferring mutations in the SdhB subunit of respiratory complex II and impact on fitness and mycotoxin production in Pencillium expansum laboratory strains. Pestic. Biochem. Physiol. 138:97-103.

Mallik, I., Arabiat, S., Pasche, J. S., Bolton, M. D., Patel, J. S., and Gudmestad, N. C. 2014. Molecular characterization and detection of mutations associated with resistance to succinate dehydrogenase-inhibiting fungicides in Alternaria solani. Phytopathology 104:40-49.

Markoglou, A. N., Malandrakis, A. A., Vitoratos, A. G., and Ziogas, B. N. 2006 Characterization of laboratory mutants of Botrytis cinerea resistant to QoI fungicides. Eur. J. Plant Pathol. 115:149-162.

Masner, P., Muster, P., and Schmid, J. 1994. Possible methionine biosynthesis inhibition by pyrimidinamine fungicides. Pestic. Sci. 42:163-166.

Mikaberidze, A., McDonald, B. A., and Bonhoeffer, S. 2014. Can high-risk fungicides be used in mixtures without selecting for fungicide resistance? Phytopathology 104:324-331.

Milgroom, M. G., Levin, S. A., and Fry, W. E. 1989. Population genetics theory and fungicide resistance. Pages 340-367 in: Plant Disease Epidemiology. 2. Genetics, Resistance and Management. K. J. Leonard and W. E. Fry, eds. McGraw Hill, New York.

Milliken, G. A., and Johnson, D. E. 1992. One-way treatment structure in a completely randomized design with heterogenous errors. Pages $16-28$ in: Analysis of Messy Data. Vol. I Designed Experiments. Chapman and Hall, London.

Miyamoto, T., Ishii, H., Seko, T., Kobori, S., and Tomita, Y. 2009. Occurrence of Corynespora cassiicola isolates resistant to boscalid on cucumber in Ibaraki Prefecture, Japan. Plant Pathol. 58:1144-1151.

Moyano, C., Gomez, V., and Melgarejo, P. 2004. Resistance to pyrimethanil and other fungicides in Botrytis cinerea populations collected in vegetable crops in Spain. J. Phytopathol. 152:484-490.

Myresiotis, C. K., Karaoglanidis, G. S., and Tzavella-Klonari, K. 2007. Resistance of Botrytis cinerea isolates from vegetable crops to anilinopyrimidine, phenylpyrrole, hydroxyanilide, benzimidazole, and dicarboximide fungicides. Plant Dis. 91 407-413.

Pasche, J. S., and Gudmestad, N. C. 2008. Prevalence, competitive fitness and impact of the F129L mutation in Alternaria solani from the United States. Crop Prot. 27:427-435

Pasche, J. S., Piche, L. M., and Gudmestad, N. C. 2005. Effect of the F129L mutation in Alternaria solani on fungicides affecting mitochondrial respiration. Plant Dis. 89:269-278

Pasche, J. S., Wharam, C. M., and Gudmestad, N. C. 2004. Shift in sensitivity of Alternaria solani in response to QoI fungicides. Plant Dis. 88:181-187.

Peever, T., and Milgroom, M. 1995. Fungicide resistance: Lessons for herbicide resistance management? Weed Technol. 9:840-849. 
Peever, T. L., and Milgroom, M. G. 1994. Lack of correlation between fitness and resistance to sterol biosynthesis-inhibiting fungicides in Pyrenophora teres. Phytopathology 84:515-519.

Pscheidt, J. W., and Stevenson, W. P. 1988. The critical period for control of early blight (Alternaria solani) of potato. Am. Potato J. 65:425-438.

Rallos, L. E. E., Johnson, N. G., Schmale, D. G., III, Prussin, A. J., II, and Baudoin, A. B. 2014. Fitness of Erysiphe necator with G143A-based resistance to quinone outside inhibitors. Plant Dis. 98:1494-1502.

Shaner, G., and Finney, R. E. 1977. The effect of nitrogen fertilization on the expression of slow-mildewing resistance in Knox wheat. Phytopathology 67:1051-1056.

Sierotzki, H., and Scalliet, G. 2013. A review of current knowledge of resistance aspects for the next generation succinate dehydrogenase inhibitor fungicides. Phytopathology 103:880-887.

Sierotzki, H., Wullschleger, J., and Gisi, U. 2000. Point-mutation in cytochrome b gene conferring resistance to strobilurin fungicides in Erysiphe graminis f. sp. tritici field isolates. Pestic. Biochem. Physiol. 68:107-112.

Stevenson, K. L., Langston, D. B., and Sanders, F. 2008. Baseline sensitivity and evidence of resistance to boscalid in Didymella bryoniae. (Abstr.) Phytopathology 98:S151.
Tymon, L., and Johnson, D. A. 2014. Fungicide resistance of two species of Alternaria from potato in the Columbia Basin of Washington. Plant Dis. 98:1648-1653.

Veloukas, T., Kalogeropoulou, P., Markoglou, A. N., and Karaoglanidis, G. S 2014. Fitness and competitive ability of Botrytis cinerea field isolates with dual resistance to SDHI and QoI fungicides, associated with several sdhB and the cytb G143A mutations. Phytopathology 104:347-356.

Wong, F. P., and Wilcox, W. F. 2002. Sensitivity to azoxystrobin among isolates of Uncinula necator: Baseline distribution and relationship to myclobutanil sensitivity. Plant Dis. 86:394-404.

Xiao, C. L., Kim, Y. K., and Boal, R. J. 2011. First report of occurrence of pyrimethanil resistance in Penicillium expansum from stored apples in Washington State. Plant Dis. 95:72.

Yellareddygari, S. K. R., Pasche, J. S., Taylor, R. J., and Gudmestad, N. C. 2016. Individual participant data meta-analysis of foliar fungicides applied for potato early blight management. Plant Dis. 100:200-206.

Zhao, H., Kim, Y. K., Huang, L., and Xiao, C. L. 2010. Resistance to thiabendazole and baseline sensitivity to fludioxonil and pyrimethanil in Botrytis cinerea populations from apple and pear in Washington State. Postharvest Biol. Technol. 56:12-18. 